\title{
Pleuroparenchymal fibroelastosis: one more walk on the wild side of drugs?
}

\author{
Philippe Camus ${ }^{1,2}$, Jan von der Thüsen ${ }^{3}$, David M. Hansell ${ }^{4}$ and Thomas V. Colby ${ }^{5}$ \\ Affiliations: 'Dept of Pulmonary Medicine and Intensive Care, Centre Hospitalier Universitaire Le Bocage, \\ Dijon, France. ${ }^{2}$ Faculté de Médecine, Université de Bourgogne, Dijon, France. ${ }^{3}$ Dept of Pathology, Medisch \\ Centrum Haaglanden, Den Haag. The Netherlands. ${ }^{4 D e p t}$ of Thoracic Imaging, National Heart and Lung \\ Institute, Imperial College London, Royal Brompton and Harefield NHS Foundation Trust, London, UK. ${ }^{5}$ Dept of \\ Laboratory Medicine and Pathology, Mayo Clinic, Scottsdale, AZ, USA.
}

Correspondence: Philippe Camus, Dept of Pulmonary Medicine and Intensive Care, Centre Hospitalier Universitaire Le Bocage, 14 rue Paul Gaffarel, 21079 Dijon, France. E-mail: ph.camusachu-dijon.fr

0 @ERSpublications

Histology of alkylating chemotherapy in PPFE patients; drugs may cause this rare pattern of lung disease http://ow.ly/yEuOz

In this issue of the European Respiratory Journal, BEYNAT-MOUTERDE et al. [1] report on six young adults (three of whom were female) who developed a clinical imaging pattern of predominant upper lobe fibrosis with apical pneumothoraces (fig. 1). Presentation in all six patients was similar with cough, dyspnoea, occasional chest pain and weight loss. Imaging was distinctive and showed a cephalad, irregular, pleuralbased thickening that encroached on the lung bilaterally. Five patients presented with "platythorax" (fig. 2), a preferential reduction in the anterio-posterior diameter of the chest wall. In all patients, severe restrictive or restrictive-obstructive lung dysfunction progressed to hypoxaemic and hypercarbic respiratory failure, which was fatal in four patients despite intensive care unit support. This outcome was all the more tragic as these four patients had survived previous malignant conditions, including haematological malignancy $(\mathrm{n}=3)$ and brain tumour $(\mathrm{n}=1)$.

Pathology in four patients showed a pattern consistent with pleuropulmonary fibroelastosis (PPFE). Due to similar clinical imaging presentation, two additional patients without biopsy were included in the study of Beynat-Mouterde et al. [1]. There was a history (6 months to 16 years previously) of multi-agent chemotherapy in all six patients; the alkylators cyclophosphamide $(\mathrm{n}=5)$ and $\mathrm{BCNU}$ (bis-chloroethylnitrosourea; $\mathrm{n}=1$ ) were the common denominators in their treatment. BEYNAT-Mouterde et al. [1] raised the possibility that alkylating drugs may have triggered or caused PPFE. Issues raised by their study relate to: 1) PPFE as a clinically, radiographically and pathologically separate and recognisable entity; 2) possible aetiological factors at the origin of PPFE, including drugs; and 3) current management strategies.

PPFE (as reviewed recently [2]) is an unusual interstitial lung disease with circumscribed fibrosis of the pleura and subjacent lung, which is of interest to pathologists [3-8], pulmonologists $[3,4,6-8]$ and radiologists $[3-6,8,9]$. Although elastosis has also been described in the heart and skin, it appeared to be confined clinically and on imaging to the pleura and lung in cases of PPFE. The condition does not clearly fit into any of the previously described interstitial pneumonias and, thus, is now specifically included in the classification of idiopathic interstitial pneumonias (IIP) under the heading "rare IIP" [2, 10]. The six patients in the study by BeYNAT-MOUTERDE et al. [1] are reminiscent of the 78 cases (59 in the English literature) of PPFE that have been published since the initial reports from Japanese investigators (to whom credit is due), under the term "upper lobe fibrosis" or "Amitani's disease" [11-13], as well as initial reports in the western world by FranKEL et al. [3]. The three largest series of PPFE included nine [14] 12 [8] and 15 [15] cases, respectively. PPFE emerges as a distinctive array of clinical, imaging and pathological abnormalities

Received: May 142014 | Accepted after revision: July 012014

Conflict of interest: None declared.

Copyright @ERS 2014 

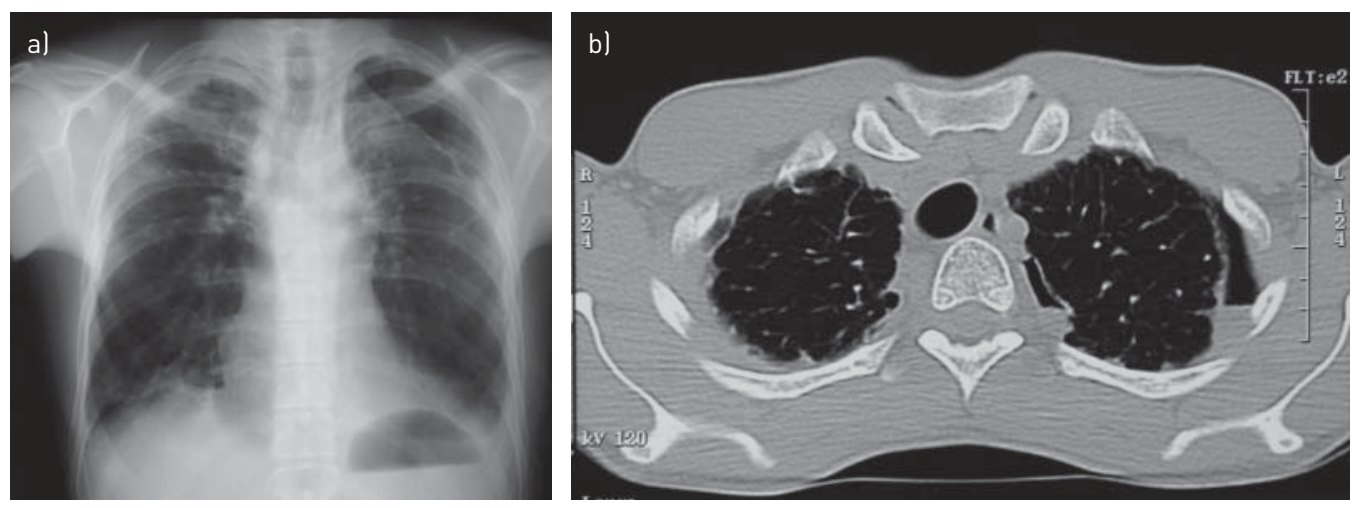

FIGURE 1 a) Frontal chest radiograph in a patient following chemotherapy for acute lymphoblastic leukaemia showing a typical appearance of pleuropulmonary fibroelastosis (corresponding to case 2 in [1]). Note the markedly thickened pleural dome on the right and partial spontaneous pneumothorax on the left. b) Computed tomography scan of the same patient taken several months later. A chest tube had been inserted and removed in the interim. A smaller, persistent pneumothorax is visible.

affecting the apices and lateral aspects of the lung and pleura bilaterally. The condition has a variable prognosis with substantial mortality $[2,8]$. Of potential teleological interest, a nearly identical condition has recently been described in a third of aged donkeys at necropsy $[16,17]$. Of note, PPFE affects the dorsal aspect of both lungs in the donkey $[17,18]$, which is the nondependent part of the lung in quadrupeds. In humans PPFE affects the lung apices which are the nondependent parts of the human lung [18].

As the name implies, PPFE is a morphologically descriptive term denoting intense elastotic fibrosis of the visceral pleura and subjacent lung and collagenous fibrosis rich in haphazardly arranged elastic fibres (figs 3 and 4). Elastosis is a distinctive form of chronic scarring in the lung that differs from the common scarring seen in idiopathic pulmonary fibrosis (IPF). PPFE lungs contain twice as much elastin compared to IPF

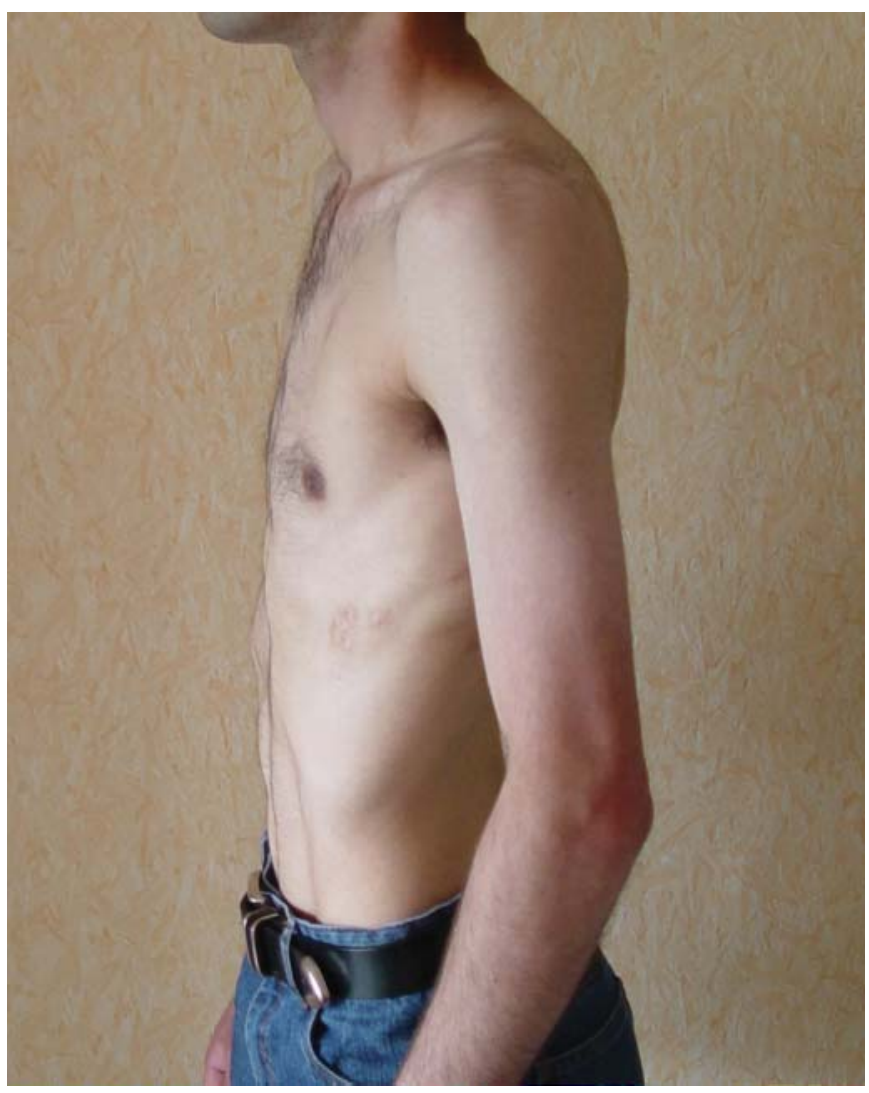

FIGURE 2 Advanced cases may show markedly restrictive physiology and reduced anterio-posterior diameter of the thorax; a trait known as platythorax. 
FIGURE 3 Gross pathology of the lung showing grey elastotic fibrosis in the subpleural regions and around the bronchovascular bundles.

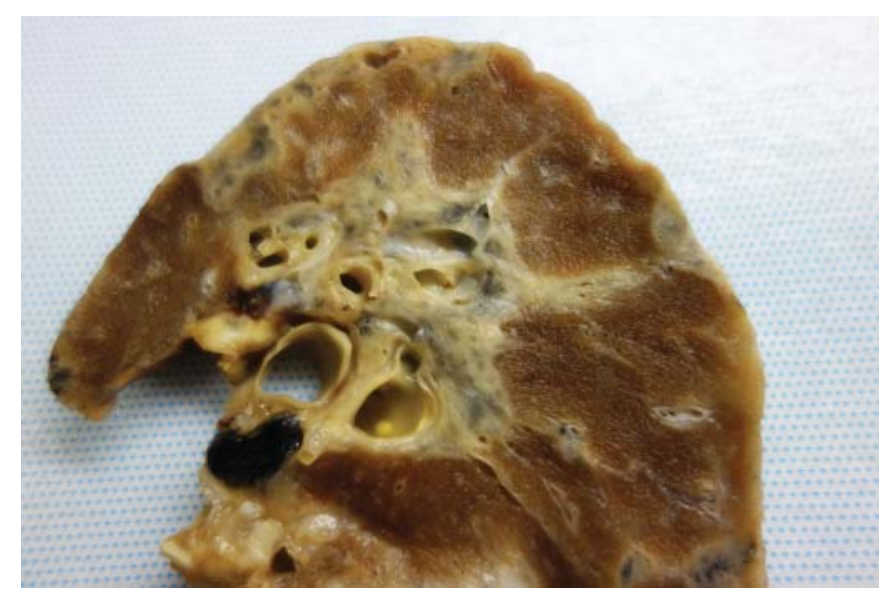

[19]. The process may extend into the septa and deeper into the lung (figs 3 and 4) [8, 20]. Elastic fibres are best visualised using orcein or Verhoeff van Gieson elastic stain (fig. 4b). The histopathological diagnosis of PPFE can still be considered without performing the specific latter elastic fibre stains, because the features on Haematoxylin and Eosin are characteristic once one is familiar with them. On microscopy, the boundary between the pleuropulmonary fibrotic area and the relatively spared juxtaposed lung is characteristically sharp [2-4, 6-8, 21]. Associated pathological features include an absence of classic honeycombing, inconspicuous fibroblastic foci, a sparse mononuclear lymphocytic infiltrate and moderate interstitial fibrosis in the remaining lung. Diffuse alveolar damage, alveolar haemorrhage [15] and/or obliterative bronchiolitis $[6,15]$ may be concomitant findings in patients who have had lung or bone marrow/ haematopoietic stem cell transplantation $[15,22]$. As a generalisation, both the pleural surface and the underlying lung are less affected or appear normal in the lower zones. The changes on gross pathology match those on imaging (figs 3 and 4) $[8,23,24]$.

Clinically, idiopathic PPFE affects males and females equally, and preferentially nonsmokers with a proportion of patients being relatively young [2]. Compared to IPF, PPFE patients have a lower body mass index and more severe restrictive lung dysfunction [19]. Onset in childhood is associated with poorer outcome $[20,25]$, possibly because the restricted fibrotic pleura and lung significantly impede lung growth $[20,25]$. Presenting features include chronic dull pleuritic pain with episodes of a sharper quality (which may not reflect pneumothorax in all patients), platythorax [26] (which can be measured on computed tomography (CT) or with a calliper), and small chronic spontaneous uni- or bilateral pneumothoraces [27]. On imaging, the fibrotic pleura and subjacent collapsed and fibrotic lung manifest as a dense irregular peripheral rim $[1,8]$. Wedge-shaped pleural-based densities protrude along parenchymal septa toward the hila $[8,9]$, and the latter tend to be retracted upwards (figs 1 and 3) [24]. Calcifications have not been reported within the thickened pleura [8], which helps to separate PPFE from asbestos-induced pleural thickening; a condition that may also affect the apical pleura, although very rarely [28]. In PPFE, there are usually features of established fibrosis away from the subpleural regions in the more central parts of the upper lobes on CT $[8,24]$. Although it may take years for PPFE to develop before patients become symptomatic and seek medical attention [1], some cases develop and progress rapidly. Once PPFE becomes symptomatic, patients may remain stable for a long period of time or progress inexorably to hypercarbic respiratory failure. Then, outcome is poor despite ventilatory support with a $40-66 \%$ mortality rate in a few years with or without an identifiable abrupt exacerbation [1, 2, 6, 8, 25, 29]. Spontaneous partial, apical, uni- or bilateral pneumothorax is a marker of abnormality for PPFE, and is present at some point in $\sim 30 \%$ of overall patients $[2,30]$. This complication was seen in five out of the six patients in the study by BEYNAT-Mouterde et al. [1]. Some pneumothoraces are small and may be simply observed [9]. Suggested mechanisms leading to pneumothoraces include cysts present in the apical fibrotic area, altered resistance of the pleura to shear stress, parenchymal bullae in the lung transplant recipient and air trapping upstream to obliterative bronchiolitis. Pneumothoraces rarely absorb spontaneously, and persistent air leak and poor reexpansion of the underlying lung are common [2]. Lung or pleural biopsy must be avoided. Many consider it unnecessary in cases that fit clinically and radiologically for PPFE. In addition, post-operative iatrogenic pneumothorax commonly complicates the procedure $[1,8]$. To the extent that the biopsy will provide more than a mere academic diagnosis, it should be considered solely as a companion procedure if surgical cure of pneumothorax is contemplated. While a definitive diagnosis of PPFE traditionally requires histological examination of the pleuropulmonary interface, a sizeable number of the patients will not undergo the 

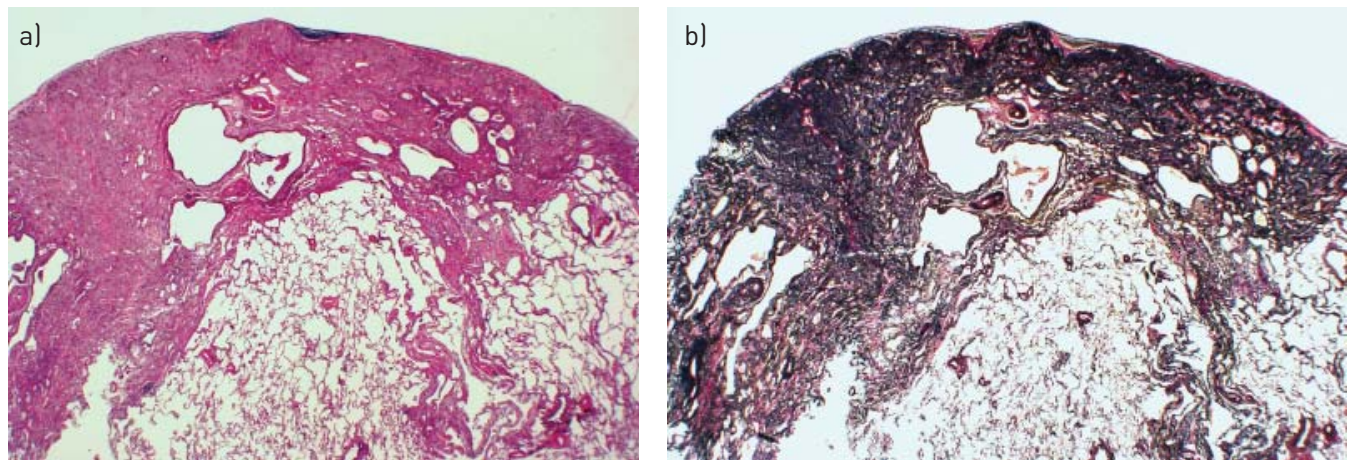

FIGURE 4 Histology staining showing a sharply demarcated zone of subpleural fibrosis with abundant elastic tissue on elastic tissue stain. a) Haematoxylin and Eosin stain and b) Verhoeff van Gieson elastic stain. Scanning power microscopy $\sim 40 \times$.

procedure. The reasons for refraining from doing so include: very advanced disease; poor ventilatory reserve; lack of perceived benefit as no treatment is available for the condition; and the fact that the disease can be strongly suspected on clinical and radiological grounds. For those cases where no biopsy is available, a label of "consistent with PPFE" has been proposed $[2,8]$, with the acronym PPFE being reserved for pathologically documented cases [8]. A study in donkeys has shown the potential merit of chest ultrasonography as a noninvasive test to diagnose PPFE (table 1) [17]. Since the disease has now been well defined, it is likely that more and more patients will be diagnosed with PPFE noninvasively.

However suggestive the clinical and imaging presentation of PPFE is, other aetiologies of pleural thickening should be considered [31, 32], including: tuberculosis and tuberculosis pneumothorax treatment; aspergillosis [1,33], although aspergillosis may complicate the course of established PPFE [33] as shown in one patient in [1]; other infections; connective tissue disease with rheumatoid arthritis lupus and ankylosing spondylitis [31]; ulcerative colitis [26]; haemothorax; a history of coronary artery bypass graft [34]; exposure to asbestos [35]; and rare or orphan pleural disease [32]. In most of these conditions, pleural thickening has a predilection to involve the lung bases or to predominate on one side, as opposed to PPFE. The differential diagnosis is usually resolved by: reviewing earlier imaging; searching for extrathoracic involvement that is typically absent in PPFE; appropriate laboratory tests for tuberculosis, aspergillosis, other infections and connective tissue diseases; and mineral dust study of bronchoalveolar lavage fluid. Asbestos pleural thickening is typically more prominent in the parietal pleura and shows the histological characteristic basket-weave collagenous appearance without any admixture of elastotic and fibrotic tissue [36].

The apical cap is a well-known, generally idiopathic lesion of the lung apices that is preferentially found in males of older age [37-39]. The apical cap is in the form of a subpleural pyramidal or spiculated scar spanning 0.7 to $5.2 \mathrm{~cm}$ in diameter. Apical caps can be large and simulate a neoplasm [37], but they do not involve the pleura circumferentially like PPFE. On pathological investigation, the cap also corresponds to dense collagen and curls or folded elastic fibres [37-39]. Time may tell whether the apical cap and PPFE share more than morphologic similarity.

Regarding aetiology, the majority of PPFE cases $(>50 \%)$ have been reported as a late complication of bone marrow/haematopoietic stem cell $[2,6]$ and lung transplantation $[2,6,40]$, for which the terms "upper lobe fibrosis" [29, 40] and "chronic lung allograft dysfunction" [41] have been applied. The prevalence of PPFE in lung transplant recipients may be as high as 2\% [29]. Rare familial occurrences of "consistent with" and bona fide PPFE have been described in young individuals, mostly females $[3,42] .10 \%$ of PPFE cases developed in patients previously exposed to chemotherapeutic agents, sometimes many years after management of the primary disease $[1,2,20,25,43]$.

Drugs are a cause célèbre of respiratory injury [44]. Pleural reactions have been known to be a result of drug injury since the 1960s [45, 46], accounting for $7 \%$ of all respiratory reactions to drugs [44]. Pleural reactions include an effusion with or without pleural eosinophilia, antinuclear-antibody positive effusion (the lupus syndrome), haemothorax, acute pleuritis and pleural thickening [44]. Reactions to ergots (e.g. bromocritptine, ergotamine, lisuride, and methysergide) may result in pleural effusion and/or pleural and pericardial thickening or fibrosis [44, 46, 47]. Individuals with a history of exposure to asbestos may be at a higher risk of developing pleural thickening if exposed to ergot drugs $[48,49]$. However, ergot-induced pleural disease differs from PPFE in that pleural thickening usually localises at the 
TABLE 1 Diagnostic features of pleuropulmonary fibrosis (PPFE)

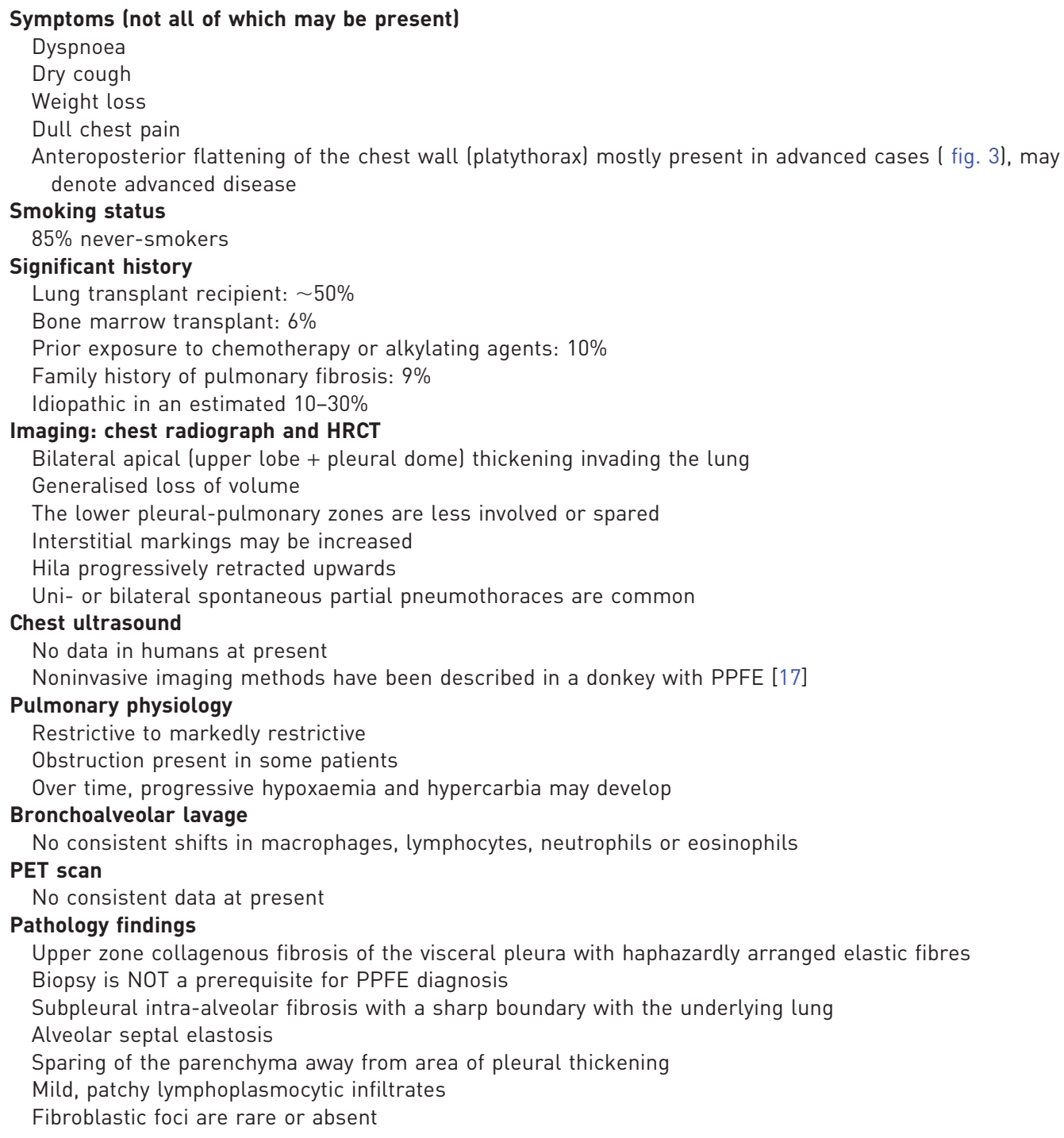

HRCT: high-resolution computed tomography; PET: positron emission tomography. For more details see [2].

lung bases and develops during therapy with the agent; although the pleura rarely returns to a normal state, pleural disease does improve after drug discontinuation [47, 48]. Furthermore, there is no evidence for increased elastic fibres on pathology in ergot-induced pleural thickening [47].

Cases of PPFE and cases which appear to be consistent with PPFE as a result of chronic complications of BCNU treatment [20, 23, 25, 50-52] or cyclophosphamide [3, 43, 53, 54] used to treat breast cancer [3], brain tumours $[20,23,51]$ or granulomatous polyangiitis [53] have been previously published, supporting the findings of Beynat-Mouterde et al. [1]. Studies by O'DrisColl and co-workers [20, 25], TAYlor et al. [23] and HASLETON et al. [51] have detailed the clinical, imaging and pathological features of late BCNU toxicity. The disease develops after a symptom-free interval of 2-12 years. Affected individuals present with the characteristic clinical, imaging and pathological features of PPFE, including pneumothorax and interstitial elastosis $[20,51]$. Craniospinal irradiation in those patients with a brain tumour was not thought to contribute to their disease as the dose received to the chest was minimal [20]. Similarly, MALIK et al. [43] reported on five cases of late pleuropulmonary toxicity developing 6 months to 6 years after termination of treatment with cyclophosphamide. Apical pleuropulmonary fibrosis involvement was also observed. Three out of the five patients died due to respiratory failure [43]. The authors reviewed five similar cases from the 
literature [43]. All the previously reported BCNU and cyclophosphamide cases closely resemble those reported by BEYNAT-MOUTERDE et al. [1].

Although appealing, the nature of an association of alkylating agents and PPFE, either causal or circumstantial, needs be examined carefully [55]. The case against causal association, includes the possibility that PPFE can develop idiopathically or, as some reports suggest, as an abreaction to infectious agents [2], as well as: due to the lack of a clear dose-response curve; development and progression of fibrosis after a free interval of several years after termination of treatment; lack of reversal with drug withdrawal; and absence of robust epidemiological support or absence of a suitable animal model [55]. Current models of pleural fibrosis use transforming growth factor- $\beta 1$, bleomycin and carbon black instilled in the pleural space as the inciting agents $[56,57]$. Conversely, in favour of an association between alkylating agents and PPFE are: the normalcy of pre-therapy chest imaging in the study by BEYNAT-MOUTERDE et al. [1]; the homogenous and consistent reports of the same distinctive drug-associated disease from different countries over the past 35 years [2]; the notion that two separate alkylating agents can produce an association with PPFE; and the occurrence of PPFE in young individuals $[20,25]$ in whom fibrotic conditions are relatively rare. Evidence for drug-associated elastosis in organs other than the pleura and lung is extremely scarce, with only one reported case of endocardial fibroelastosis following therapy with adriamycin [58].

Management of this dreadful condition is difficult. Corticosteroids and immunosuppressants offer transitory or no improvement, even less cure; except in a very few cases. Pleuropulmonary biopsy should be undertaken very cautiously, if at all. Experience with decortication is extremely limited [59]. Timely consultation with a transplant team is warranted, as transplantation has been suggested [4, 5] and successfully attempted in a few cases $[42,60]$.

To conclude, the imaging features of PPFE are very suggestive, if not pathognomonic. PPFE is a probable if not frequent late complication of chemotherapy regimens containing alkylating agents. As greater awareness of PPFE will lead to more frequent and hopefully more accurate diagnosis and reporting, we can only hope this will improve our comprehension of PPFE and its causes, including drug therapy, enabling novel treatment approaches to be identified, thus, improving the currently poor outcome.

\section{Acknowledgements}

We would like to thank Nicolas Baudouin (Dept of Pulmonary Medicine and Intensive Care, Centre Hospitalier Universitaire Le Bocage, Dijon, France), who diligently cared for several patients in our intensive care unit who were included in the study by C. Beynat-Mouterde and co-workers. Title in tribute to Lou Reed (1942-2013).

\section{References}

1 Beynat-Mouterde C, Beltramo G, Lezmi G, et al. Pleuroparenchymal fibroelastosis as a late complication of chemotherapy agents. Eur Respir J 2014; 44: 523-527.

2 von der Thüsen JH. Pleuroparenchymal fibroelastosis: its pathological characteristics. Curr Respir Med Rev 2013; 9: 238-247.

3 Frankel SK, Cool CD, Lynch DA, et al. Idiopathic pleuroparenchymal fibroelastosis: description of a novel clinicopathologic entity. Chest 2004; 126: 2007-2013.

4 Becker CD, Gil J, Padilla ML. Idiopathic pleuroparenchymal fibroelastosis: an unrecognized or misdiagnosed entity? Mod Pathol 2008; 21: 784-787.

5 Piciucchi S, Tomassetti S, Casoni G, et al. High resolution CT and histological findings in idiopathic pleuroparenchymal fibroelastosis: features and differential diagnosis. Respir Res 2011; 12: 111.

6 von der Thüsen JH, Hansell DM, Tominaga M, et al. Pleuroparenchymal fibroelastosis in patients with pulmonary disease secondary to bone marrow transplantation. Mod Pathol 2011; 24: 1633-1639.

7 Larsen BT, Colby TV. Update for pathologists on idiopathic interstitial pneumonias. Arch Pathol Lab Med 2012; 136: 1234-1241.

8 Reddy TL, Tominaga M, Hansell DM, et al. Pleuroparenchymal fibroelastosis: a spectrum of histopathological and imaging phenotypes. Eur Respir J 2012; 40: 377-385.

9 Sverzellati N, Zompatori M, Poletti V, et al. Small chronic pneumothoraces and pulmonary parenchymal abnormalities after bone marrow transplantation. J Thorac Imaging 2007; 22: 230-234.

10 Travis WD, Costabel U, Hansell DM, et al. An official American Thoracic Society/European Respiratory Society statement: update of the international multidisciplinary classification of the idiopathic interstitial pneumonias. Am J Respir Crit Care Med 2013; 188: 733-748.

11 Amitani R, Niimi A, Kuse F. [Idiopathic pulmonary upper lobe fibrosis (IPUF)]. Kokyu 1992; 11: 693-699.

12 Kobayashi Y, Sakurai M, Kushiya M, et al. [Idiopathic pulmonary fibrosis of the upper lobe: a case report]. Nihon Kokyuki Gakkai Zasshi 1999; 37: 812-816.

13 Shiota S, Shimizu K, Suzuki M, et al. [Seven cases of marked pulmonary fibrosis in the upper lobe]. Nihon Kokyuki Gakkai Zasshi 1999; 37: 87-96.

14 Kusagaya $\mathrm{H}$, Nakamura $\mathrm{Y}$, Kono $\mathrm{M}$, et al. Idiopathic pleuroparenchymal fibroelastosis: consideration of a clinicopathological entity in a series of Japanese patients. BMC Pulm Med 2012; 12: 72.

15 Ofek E, Sato M, Saito T, et al. Restrictive allograft syndrome post lung transplantation is characterized by pleuroparenchymal fibroelastosis. Mod Pathol 2013; 26: 350-356.

16 Morrow LD, Smith KC, Piercy RJ, et al. Retrospective analysis of post-mortem findings in 1,444 aged donkeys. J Comp Pathol 2011; 144: 145-156. 
17 Miele A, Dhaliwal K, Du Toit N, et al. Chronic pleuropulmonary fibrosis and elastosis of aged donkeys similarities to human pleuroparenchymal fibroelastosis (PPFE). Chest 2014; 145: 1325-1332.

18 Wagner PD, Saltzman HA, West JB. Measurement of continuous distributions of ventilation-perfusion ratios: theory. J Appl Physiol 1974; 36: 588-599.

19 Enomoto N, Kusagaya H, Oyama Y, et al. Quantitative analysis of lung elastic fibers in idiopathic pleuroparenchymal fibroelastosis (IPPFE): comparison of clinical, radiological, and pathological findings with those of idiopathic pulmonary fibrosis (IPF). BMC Pulm Med 2014; 14: 91.

20 O'Driscoll BR, Hasleton PS, Taylor PM, et al. Active lung fibrosis up to 17 years after chemotherapy with carmustine (BCNU) in childhood. N Engl J Med 1990; 323: 378-382.

21 Hirota T, Fujita M, Matsumoto T, et al. Pleuroparenchymal fibroelastosis as a manifestation of chronic lung rejection? Eur Respir J 2013; 41: 243-245.

22 Pena E, Souza CA, Escuissato DL, et al. Noninfectious pulmonary complications after hematopoietic stem cell transplantation: practical approach to imaging diagnosis. Radiographics 2014; 34: 663-683.

23 Taylor PM, O'Driscoll BR, Gattamaneni HR, et al. Chronic lung fibrosis following carmustine (BCNU) chemotherapy: radiological features. Clin Radiol 1991; 44: 299-301.

24 Watanabe K. Pleuroparenchymal fibroelastosis: its clinical characteristics. Curr Respir Med Rev 2013; 9: 299-237.

25 O’Driscoll BR, Kalra S, Gattamaneni HR, et al. Late carmustine lung fibrosis. Age at treatment may influence severity and survival. Chest 1995; 107: 1355-1357.

26 Harada T, Yoshida Y, Kitasato Y, et al. The thoracic cage becomes flattened in the progression of pleuroparenchymal fibroelastosis. Eur Respir Rev 2014; 23: 263-266.

27 Oda $\mathrm{T}$, Ogura $\mathrm{T}$, Kitamura $\mathrm{H}$, et al. Characteristics of pleuroparenchymal fibroelastosis with usual interstitial pneumonia compared to idiopathic pulmonary fibrosis. Chest 2014 [In press DOI: 10.1378/chest.13-2866].

28 Oliver RM, Neville E. Progressive apical pleural fibrosis: a "constrictive" ventilatory defect. Br J Dis Chest 1988; 82: 439-443.

29 Pakhale SS, Hadjiliadis D, Howell DN, et al. Upper lobe fibrosis: a novel manifestation of chronic allograft dysfunction in lung transplantation. J Heart Lung Transplant 2005; 24: 1260-1268.

30 Watanabe K, Nagata N, Kitasato Y, et al. Rapid decrease in forced vital capacity in patients with idiopathic pulmonary upper lobe fibrosis. Respir Investig 2012; 50: 88-97.

31 Huggins JT, Sahn SA. Causes and management of pleural fibrosis. Respirology 2004; 9: 441-447.

32 Walker CM, Takasugi JE, Chung JH, et al. Tumorlike conditions of the pleura. Radiographics 2012; 32: 971-985.

33 Kurosaki F, Bando M, Nakayama M, et al. Clinical features of pulmonary aspergillosis associated with interstitial pneumonia. Intern Med 2014; 53: 1299-1306.

34 Light RW, Rogers JT, Moyers JP, et al. Prevalence and clinical course of pleural effusions at 30 days after coronary artery and cardiac surgery. Am J Respir Crit Care Med 2002; 166: 1567-1571.

35 Jeebun V, Stenton SC. The presentation and natural history of asbestos-induced diffuse pleural thickening. Occup Med (Lond) 2012; 62: 266-268.

36 Stephens M, Gibbs AR, Pooley FD, et al. Asbestos induced diffuse pleural fibrosis: pathology and mineralogy. Thorax 1987; 42: 583-588.

37 Yousem SA. Pulmonary apical cap: a distinctive but poorly recognized lesion in pulmonary surgical pathology. Am J Surg Pathol 2001; 25: 679-683.

38 Mugler K. Pathologic quiz case: bilateral apical lung masses in an autopsy patient. Pulmonary apical cap. Arch Pathol Lab Med 2004; 128: e35-e36.

39 Hirami Y, Nakata M, Maeda A, et al. Pulmonary apical mass, the so-called pulmonary apical cap, in a 43-year-old woman. Ann Thorac Cardiovasc Surg 2010; 16: 122-124.

40 Konen E, Weisbrod GL, Pakhale S, et al. Fibrosis of the upper lobes: a newly identified late-onset complication after lung transplantation? AJR Am J Roentgenol 2003; 181: 1539-1543.

41 Verleden SE, de Jong PA, Ruttens D, et al. Functional and computed tomographic evolution and survival of restrictive allograft syndrome after lung transplantation. J Heart Lung Transplant 2014; 33: 270-277.

42 Azoulay E, Paugam B, Heymann MF, et al. Familial extensive idiopathic bilateral pleural fibrosis. Eur Respir J 1999; 14: 971-973.

43 Malik SW, Myers JL, DeRemee RA, et al. Lung toxicity associated with cyclophosphamide use. Two distinct patterns. Am J Respir Crit Care Med 1996; 154: 1851-1856.

44 Pneumotox Online. The Drug-Induced Respiratory Disease Website. v2. www.pneumotox.com Date last updated: June 29, 2014. Date last accessed: June 30, 2014.

45 Ladd AT. Procainamide-induced lupus erythematosus. N Engl J Med 1962; 267: 1357-1358.

46 Graham JR. Cardiac and pulmonary fibrosis during methysergide therapy for headache. Trans Am Clin Climatol Assoc 1967; 78: 79-92.

47 Pfitzenmeyer P, Foucher P, Dennewald G, et al. Pleuropulmonary changes induced by ergoline drugs. Eur Respir J 1996; 9: 1013-1019.

48 Knoop E, Mairesse M, Lenclud C, et al. Pleural effusion during bromocriptine exposure in two patients with preexisting asbestos pleural plaques: a relationship? Eur Respir J 1997; 10: 2898-2901.

49 De Vuyst P, Pfitzenmeyer P, Camus P. Asbestos, ergot drugs and the pleura. Eur Respir J 1997; 10: 2695-2698.

50 Bailey CC, Marsden HB, Morris Jones PH. Fatal pulmonary fibrosis following 1, 3-bis(2-chloroethyl)-1-nitrosourea therapy. Cancer 1978; 42: 74-76.

51 Hasleton PS, O’Driscoll BR, Lynch P, et al. Late BCNU lung: a light and ultrastructural study on the delayed effect of BCNU on the lung parenchyma. J Pathol 1991; 164: 31-36.

52 Myers JL, Limper AH, Swensen SJ. Drug-induced lung disease: a pragmatic classification incorporating HRCT appearances. Semin Respir Crit Care Med 2003; 24: 445-454.

53 Stentoft J. Progressive pulmonary fibrosis complicating cyclophosphamide therapy. Acta Med Scand 1987; 221: 403-407.

54 Hamada K, Nagai S, Kitaichi M, et al. Cyclophosphamide-induced late-onset lung disease. Intern Med 2003; 42 : $82-87$.

55 Hill AB. The environment and disease: association or causation? Proc R Soc Med 1965; 58: 295-300. 
56 Decologne N, Kolb M, Margetts PJ, et al. TGF- $\beta 1$ induces progressive pleural scarring and subpleural fibrosis. J Immunol 2007; 179: 6043-6051.

57 Decologne N, Wettstein G, Kolb M, et al. Bleomycin induces pleural and subpleural fibrosis in the presence of carbon particles. Eur Respir J 2010; 35: 176-185.

58 Conroy B, Guthrie W. Endocardial fibroelastosis associated with fatal adriamycin (doxorubicin) cardiomyopathy during treatment of Ewing's sarcoma. Scott Med J 1983; 28: 295-299.

59 Boffa DJ, Mason DP, Su JW, et al. Decortication after lung transplantation. Ann Thorac Surg 2008; 85: 1039-1043.

60 Santamauro JT, Stover DE, Jules-Elysee K, et al. Lung transplantation for chemotherapy-induced pulmonary fibrosis. Chest 1994; 105: 310-312. 